\title{
Does leaving school in an economic downturn impact access to employer-sponsored health insurance?
}

Johanna Catherine Maclean

\author{
Correspondence: \\ catherine.maclean@temple.edu \\ Department of Economics, Temple \\ University, Ritter Annex 869-1301, \\ Cecil B Moore Avenue, Philadelphia, \\ PA 19122, USA
}

\begin{abstract}
Previous work documents that leaving school in an economic downturn persistently depresses career outcomes as measured by wages, earnings, and other markers of labor market success. In this study I test whether leaving school in an economic downturn influences access to employer-sponsored health insurance. Using a long panel of workers drawn from the National Longitudinal Survey of Youth 1979 Cohort, I model the likelihood that a worker has access to employer-sponsored health insurance from initial labor market entrance through mid-career. I address the potential endogeneity of time and location of school-leaving with instrumental variables. My results suggest that leaving school in an economic downturn lowers the probability of access to employer-sponsored health insurance and this disparity is statistically distinguishable from zero 18 years after school-leaving.

JEL codes: $11 ; 112 ; J 3$

Keywords: Employer-sponsored health insurance; Fringe benefits; School-leaving; Macroeconomic fluctuations
\end{abstract}

\section{Introduction}

In this study I provide the first evidence on the persistent impact of leaving school in an economic downturn on access to employer-sponsored health insurance. This work is based on a growing line of research that documents persistent negative career effects - as measured by earnings, occupational prestige, and probability of promotion - for individuals who leave school in an economic downturn (Genda et al. 2010; Kahn 2010; Oreopoulos et al. 2012; Oyer 2006, 2008). Non-monetary forms of compensation (or fringe benefits), such as health insurance, can hold substantial value for employees. For example, the average annual cost of an employer-sponsored family health insurance plan was $\$ 16,351$ in 2013 and employers covered $71 \%$ of this cost (Claxton et al. 2013). Because of its high monetary value, and preferential tax treatment, employer-sponsored health insurance represents an important component of full compensation.

Health insurance is important to consider for at least two reasons beyond simply better measuring compensation. First, standard models of the demand for health highlight the importance of medical services (Grossman 1972). Health insurance, by lowering the monetary cost faced by the consumer, will increase the quantity of medical services 
demanded which may, in turn, improve health outcomes. Second, health insurance offers protection against financial instability generated by health shocks and their associated medical costs (Finkelstein et al. 2012; Gross and Notowidigdo 2011; Himmelstein et al. 2009).

Those who do not have access to employer-sponsored health insurance, and wish to obtain private coverage, must purchase insurance through the individual market. An individual's ability to substitute employer-sponsored health insurance with insurance purchased in the individual market may be hampered by high costs (Whitmore et al. 2011) and insurance companies' historical ability to exclude (or charge higher premiums to) persons with pre-existing conditions (Kaiser Family Foundation 2012). Provisions (e.g., guaranteed issue) in the Patient Protection and Affordable Care Act (ACA), effective January 2014, are expected to prevent such exclusions however (111th United States Congress 2010).

Understanding determinants of access to private health insurance (employersponsored health insurance is currently the most common source of private health insurance in the U.S. (DeNavas-Walt et al. 2013)) is not simply of interest for understanding individual health and financial well-being. Instead, individuals who do not have access to private health insurance either take up public health insurance (e.g., Medicaid) or become uninsured and rely on emergency medical care. The use of both public and emergency medical care places a direct financial burden on the American taxpayer and how the U.S. will finance health care expenditures is of concern to fiscal policy makers (Chernew et al. 2009). Such concerns are likely to increase as the ACA expands access to health insurance to millions of Americans. In particular, health insurance provisions in the ACA are predicted to cost the Federal government $\$ 710$ billion between 2014 and 2019 (Congressional Budget Office 2013).

To study the effect of leaving school in an economic downturn on access to employer-sponsored health insurance, I build a long panel data set of workers from the National Longitudinal Survey of Youth 1979 Cohort (NLSY79) and model the probability of access to employer-sponsored health insurance as a function of the state unemployment rate at school-leaving. To this end I exploit variation generated by volatility in the U.S. economy between 1976 and 1996. The NLSY79 regularly collects information on access to employer-sponsored health insurance and thus allows me to track workers from school-leaving (which coincides with initial labor market entrance for many) through mid-career (members of the NLSY79 cohort are ages 45 to 53 in the last year of my data). I address the potential endogeneity of both the time and location of school-leaving with instrumental variables using instruments based on birth year and state of residence at age 14 (Kahn 2010; Kondo 2007; Maclean 2013b; Oreopoulos et al. 2012; Oyer 2006). In extensions to the main analyses I examine whether leaving school in an economic downturn influences access to a second form of non-monetary compensation (life insurance) and utilization of public health insurance as measured by Medicaid coverage.

My findings suggest that economic downturns experienced at school-leaving persistently and negatively affect access to employer-sponsored health insurance, but the effects are observed for men only. Men who leave school in an economic downturn are less likely to have access to employer-sponsored health insurance than their counterparts who left school under stronger economic conditions. My instrumental variable 
specification implies that a 1 percentage point increase in the school-leaving state unemployment rate leads to a 1.7 percentage point $(2.2 \%)$ reduction in the probability of access to employer-sponsored health insurance among men. Although the effect dissipates over time a disparity is observable and statistically distinguishable from zero 18 years after school-leaving. I find evidence that access to other forms of nonmonetary compensation, as measured by employer-sponsored life insurance, is also negatively and persistently influenced by leaving school in an economic downturn among men but not women. I do not find evidence that individuals who leave school in an economic downturn take-up public health insurance. However, data limitations prevent me from providing conclusive results.

\section{Related work}

I next briefly review several strands of economic research related to the current study: 1) health and consumer finance work on the importance of health insurance, 2) the persistent career effects of leaving school in an economic downturn, and 3) changes in the contemporaneous economic environment and access to employer-sponsored health insurance.

\subsection{Importance of health insurance for health outcomes and financial stability}

Access to health insurance plays an important role in standard economic models of the demand for health. For example, in the Grossman model (1972) health is produced using market goods (e.g., medical services) and non-market goods (e.g., time investments) as inputs. In this context, access to health insurance, employer-sponsored or otherwise, can lower the financial cost of purchasing medical services and, all else equal, increase the quantity of medical services demanded and in turn improve health outcomes ${ }^{1}$.

Empirical evidence on whether, and to what extent, access to health insurance improves health is somewhat mixed and may depend on both the type of insurance and the type of patient (Courtemanche and Zapata 2014; Currie and Gruber 1996; Finkelstein et al. 2012; Meyer and Wherry 2012; Newhouse 1993). For example, the RAND health experiment found little evidence that large differences in out-of-pocket payments lead to substantial changes in health outcomes (Newhouse 1993). Using state changes in Medicaid eligibility as a source of variation Currie and Gruber (1996) find that access to public health insurance reduces child mortality. Meyer and Wherry (2012) show that access to public health insurance during childhood reduces morality rates among adolescents, particularly among African Americans, using a discontinuity in Medicaid access that occurred nationally in the early 1980s. Courtemanche and Zapata (2014) exploit a 2006 health care reform in Massachusetts and show that access to health insurance leads to substantial health improvements across a broad range of outcomes, although effects are particularly strong for low income and non-white groups. Alternatively using experimental evidence from the Oregon Medicaid program Finkelstein et al. (2012) find that access to public insurance leads to only small improvements in self-reported health among adults. Understanding whether or not, and to what extent, access to health insurance improves health is an important question, but it is beyond the scope of this study. 
A second important benefit of health insurance is protection against financial loss that can occur following a health shock. Medical costs are a leading cause of bankruptcy among Americans. For example, Himmelstein et al. (2009) show that in 2007 $62.1 \%$ of bankruptcies were at least partially attributable to medical costs. At the same time access to health insurance can reduce out-of-pocket payments, unpaid medical bills, and medical cost-related bankruptcies (Finkelstein et al. 2012; Gross and Notowidigdo 2011). Because financial strain and debt obligations are associated with poor health (Kahn and Pearlin 2006; Zimmerman and Katon 2005), access to health insurance may indirectly improve health by reducing the occurrence of these health harming outcomes. (Bankruptcy is obviously not a desirable outcome regardless of whether or not it can be linked with health.)

\subsection{Economic work on the persistent effects of leaving school in an economic downturn}

Labor market equilibrium occurs when the supply of labor by workers equals the demand for labor by firms. Following a negative demand shock, as might occur during an economic downturn, firms demand less labor and the market clears at a lower level of total compensation which can include both wages and other forms of nonmonetary compensation (e.g., employer-sponsored health insurance). As a result, school-leavers who enter the labor market in an economic downturn may receive lower monetary and non-monetary compensation.

In addition to lower starting compensation, labor studies show that labor market frictions limit the ability of workers to shift into better jobs as the economy rebounds, leaving workers persistently stuck in low-wage and otherwise less desirable jobs (Genda et al. 2010; Kahn 2010; Kondo 2007; Kwon et al. 2010; Oreopoulos et al. 2012; Oyer 2006, 2008). For example, Kahn (2010) finds that a 1 percentage point increase in the state unemployment rate at school-leaving leads to an annual wage loss of 2.5 to $9 \%$ 15 years later among white male college graduates in the NLSY79 (the same data set I examine in the current study). Moreover, individuals who leave school in an economic downturn hold less prestigious jobs and are less likely to be promoted (Kahn 2010; Kwon et al. 2010; Schoar and Zuo 2011). However, women's labor market outcomes relative to men's outcomes - appear to be less influenced by economic conditions faced at school-leaving market (Hershbein 2012; Kondo 2007).

Two additional studies are important to consider for understanding the persistent effects of leaving school in an economic downturn. First, Neumark (2002) studies the impact of job instability (or churning) in early career on later wages. Utilizing an instrumental variables framework, where economic conditions at labor market entrance provide the identifying variation, he shows that instability in early career leads to lower adult wages. Second, Beaudry and DiNardo (1991) test whether a worker's history of labor market conditions across the career impacts current wages. The author's develop a contract model with the following predictions: 1) if mobility between jobs is limited then the unemployment rate at the time a worker was hired will predict current wage as wage contracted will only be negotiated once at the beginning of the job and 2) if mobility between jobs is high then current wages should be predicted by the strongest labor market conditions during the span of the job as wages will be re-negotiated during good economic times to prevent the worker from moving 
to a different job. Analyses of the Current Population Survey and Panel Study of Income Dynamics indicate that the lowest unemployment rate negatively predicts current wages. These studies provide further support for the concept that economic conditions at school-leaving can persistently impact career outcomes.

Several recent studies suggest that the effects of leaving school in an economic downturn may extend beyond the labor market. For example, they may also impact health and health behaviors (Cutler et al. 2014; Hessel and Avendano 2013; Maclean 2013a, b, 2014; Maclean and Hill 2013). Although findings may depend on both worker and labor market characteristics, the evidence based on U.S. samples suggests that those who leave school in an economic downturn have worse mental and physical health, lower self-esteem, and are more likely to misuse alcohol (Maclean 2013b, 2014; Maclean and Hill 2013) but they may have lower body weight (Maclean 2013a). Hershbein (2012) and Maclean et al. (2013) show that in response to leaving school in an economic downturn male workers are less likely to marry. Hofmann and Hohmeyer (2014) and Maclean et al. (2013) show that women who leave school in a downturn have children earlier and are more likely to be married.

\subsection{Changes in the contemporaneous economic environment and access to health insurance}

An important, related set of papers for the purposes of this study examines the influence of contemporaneous economic downturns on access to health insurance (Cawley et al. 2013; Cawley and Simon 2005; Marquis and Long 2001). These studies suggest that during economic downturns, individuals - in particular men - lose access to health insurance, including employer-sponsored health insurance. For example, using data from the 2004 to 2010 Survey of Income and Program Participation Cawley et al. (2013) find that a 1 percentage point increase in the state unemployment rate leads to a 1.67 percentage point $(2.12 \%)$ reduction in the probability that men have any health insurance. The authors show that women's access to health insurance is not strongly correlated with the state unemployment rate. Moreover, Marquis and Long (2001) demonstrate that employers are less likely to offer health insurance, and the offered insurance is less generous, to employees in economic downturns.

There are key differences between the body of work on contemporaneous economic downturns and access to health insurance and my study, however. In particular, this work considers transitory economic shocks among the general pool of workers while I consider an economic shock experienced during the school-to-work transition for new labor market entrants. Thus, it is not clear how well previous findings can inform us about the lasting effects of experiencing an economic downturn at the beginning of one's career.

To the best of my knowledge, no study has examined whether leaving school in an economic downturn influences the probability that an employee has access to nonmonetary forms of compensation such as employer-sponsored health. However, on net the literature seems to suggest that leaving school in an economic downturn should persistently depress the probability of access to this form of non-monetary compensation, and the effects will be stronger for men than for women. Separate consideration of this outcome is important for several reasons: health insurance can influence health 
outcomes and financial stability, and it represents an important component of total compensation. Thus, exploring access to health employer-sponsored health insurance may shed light on potential mechanisms through which leaving school in an economic downturn influences other outcomes (e.g., health) and shifts to other forms of health insurance coverage (in particular, publicly provided insurance), while failure to consider health insurance may miss-state the full compensation effects of leaving school in a downturn. In this study, I take this question to the data.

\section{Data, variables, and methods}

\subsection{Data}

To study the persistent effect of leaving school in an economic downturn on access to employer-sponsored health insurance I use data a long panel of workers from the National Longitudinal Survey of Youth 1979 Cohort (NLSY79). Previous economic studies have utilized the NLSY79 to study determinants of employer-sponsored health insurance (Cawley and Simon 2005; Simon and Kaestner 2003). The original sample consists of 12,686 youth 14 to 22 in 1979. The survey was administered annually by the Bureau of Labor Statistics (BLS) between 1979 and 1993, and bi-annually from 1994 to 2010. I exclude subsamples dropped by the NLSY79 for financial reasons (military sample in 1984 and the low income white sample in 1992). Further, I delete respondents who left school before 1976 as state-level unemployment rates from the Bureau of Labor Statistics Local Area Statistics (detailed in Section 3.3 of this manuscript) are available only from 1976 onwards and I exclude those respondents who report that they did not complete any formal education. Moreover, I exclude observations for respondents in years prior to school-leaving.

Access to employer-sponsored health insurance is collected in all rounds of the NLSY79, with the exception of 1981, leaving an analysis sample of 4,182 men and 4,439 women. Thus, my sample is comparable in terms of size to other studies that utilize the NLSY79 to examine the persistent effects of leaving school in an economic downturn (Hershbein 2012; Kahn 2010; Kondo 2007; Maclean 2013b, 2014). I focus on the unbalanced panel, in other words I use all available person/year observations, to preserve sample size. The number of person/year observations for men and women in my sample are 57,827 and 56,862.

\subsection{Employer-sponsored health insurance}

I construct an indicator for access to employer-sponsored health. The specific question wording in 1979 is "Does your employer make health insurance available to you? Medical, surgical, or hospital insurance that covers injuries or major illnesses off the job?" I code respondents one if they report this offer, and zero otherwise. NLSY79 respondents can list information, including access to employer-sponsored health insurance, on multiple jobs and the number of jobs varies across survey years. For consistency across survey years I focus here on the first reported job ${ }^{2}$. Additional information on the employer-sponsored health insurance variables is available on the NLSY79 website (https://nlsinfo.org/content/cohorts/nlsy79/topical-guide/employment/ fringe-benefits; accessed 3/5/2014).

This variable has at least three important caveats. First, this variable captures whether an employee is aware of an offer of employer-sponsored health insurance. Respondents may decide not to take up this offer for myriad reasons. For example, depressed wages 
attributable to leaving school in an economic downturn may prevent workers from purchasing health insurance offered by their employer. I am unable to capture such reasons here. Moreover, workers may not be aware of offered health insurance. Second, this variable does not measure the generosity of any offered health insurance. Previous work suggests that during economic downturns employers offer less generous insurance plans to their employees (Marquis and Long 2001), and my data do not allow me to speak to this dimension of health insurance access. Third, the employer-sponsored health insurance question described here is only asked to workers and thus my findings may be vulnerable to sample-selection bias. Previous work (Kahn 2010) finds only modest evidence that leaving school in an economic downturn influences labor supply, however.

There is some variation in both the question wording and universe across rounds of the NLSY79. An obvious concern is that changes in question wording or universe may muddle estimates of the impact of leaving school in an economic downturn on access to employer-sponsored health insurance. Additional file 1 reports the employer-sponsored health insurance question wording and universe by round, and the proportion of workers with access to employer-sponsored health insurance by survey round. The prevalence rate is substantially lower in survey years 1979, 1980, and 1982 (when respondents are between ages 14 and 25) than later years and the differences are likely too large to be explained by younger workers progressively acquiring jobs that offer health insurance. Instead, changes in the question universe are potentially driving this difference. For example, in 1979 respondents who reported any work outside the home in the past year were included in the question universe while later years added further eligibility restrictions (e.g., work $\geq$ 20 hours per week) $)^{3}$. Between 1979 and 1982 many respondents who work may be employed in jobs that do not offer health insurance (e.g., part time jobs). In unreported analyses that are available on request I re-estimate all regressions excluding survey years 1979, 1980, and 1982. Results are highly robust.

Additional file 2 reports the proportion of the sample reporting access to employersponsored health insurance by single year of age. As respondents age the proportion of the sample reporting access to employer-sponsored health insurance increases smoothly. There are no large changes in this proportion between ages.

\subsection{School-leaving}

The key explanatory variable in this study is the economic conditions at school-leaving. I focus here on the first period of school-leaving which occurs once for each respondent. The leaving school definition includes both students who graduated with a degree and who dropped out prior to degree completion. Put differently, both completers and drop-outs are included in my analysis sample. I utilize responses to education history questions fielded between 1979 and 1998 to identify the year the respondent left school for the first time. I delete respondents who have not yet left school. I exclude respondents who left school after the 1996 round $^{4}$, when respondents are 31 to 39 years of age, and require that respondents report being out of school for a period of two years after school-leaving to avoid incorrectly classifying short departures (e.g., travelling abroad for a year) as true school-leaving.

I utilize the NLSY79 geocodes to determine the state of residence at school-leaving. Respondents who left school between 1976 and 1978 are assigned the 1979 interview 
state. This assignment may lead to some measurement error in the school-leaving variables and the direction of the bias attributable to measurement error is difficult to sign (Bound et al. 2001). The interview state is assigned to respondents who left school between 1979 and 1996. The annual unweighted school-leaving cohort (where a school-leaving cohort consists of individuals who left school in the same year) sizes are reported in Table 1.

I proxy economic conditions with the seasonally unadjusted annual state unemployment rate $^{5}$. These data are drawn from the BLS Local Area Unemployment Statistics. Although no single variable can fully characterize economic activity in an economy, the unemployment rate is one of the indicators utilized by the National Bureau of Economic Research (2010) to date business cycles and by the Federal Reserve System to track economic trends. Moreover, it is commonly utilized within the literature that examines the persistent effects of leaving school in an economic downturn (Kahn 2010).

Figure 1 reports the quasi-experiment I exploit: the average annual unadjusted state unemployment rate is plotted between 1976 and 1996. During this period the U.S. experienced three recessions (January 1980 to July 1980, July 1981 to November 1982, and July 1990 to March 1991), a period of high inflation in the late-1970s. Moreover, states were differentially impacted by these economic events as evidenced by the annual minimum and maximum state unemployment rates (indicated with horizontal bars in Figure 1).

Table 1 School-leaving cohort size: NLSY79

\begin{tabular}{lc}
\hline School-leaving year & School-leaving cohort size \\
\hline 1976 & 528 \\
1977 & 765 \\
1978 & 1,146 \\
1979 & 1,283 \\
1980 & 1,104 \\
1981 & 1,067 \\
1982 & 949 \\
1983 & 588 \\
1984 & 381 \\
1985 & 253 \\
1986 & 198 \\
1987 & 123 \\
1988 & 66 \\
1989 & 54 \\
1990 & 36 \\
1991 & 13 \\
1992 & 24 \\
1993 & 14 \\
1994 & 13 \\
1995 & 13 \\
\hline 996 & 13 \\
\hline
\end{tabular}

Notes: A school-leaving cohort is defined as the number of NLSY79 respondents who left school in the same year. 


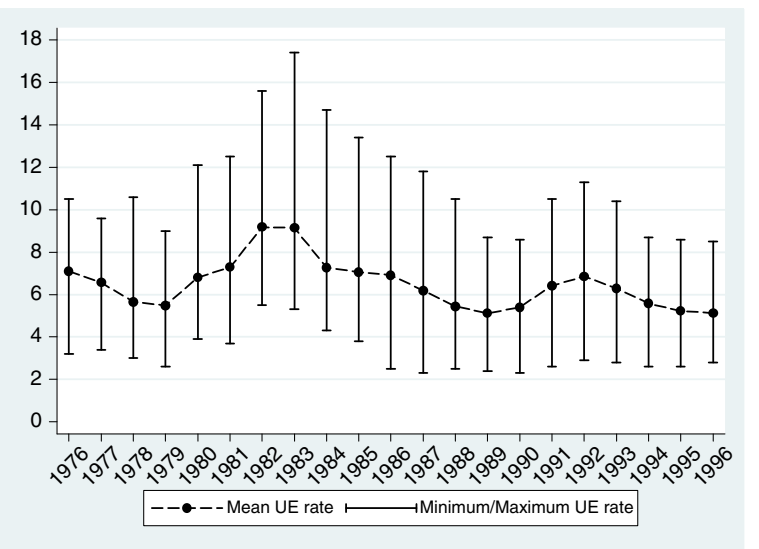

Figure 1 Average, minimum, and maximum annual state unemployment rates between 1976 and 1996. Source: Bureau of Labor Statistics Local Area Unemployment Statistics.

\subsection{Control variables}

In my core regressions I include a set of personal characteristics that are expected to predict access to employer-sponsored health insurance: age at school-leaving, years of education at school leaving (entered linearly), race/ethnicity (African American and Hispanic, with White as the omitted group), and a proxy for ability (a quadratic in the Armed Forces Qualification Test [AFQT]). Because the NLSY79 contains detailed information on family background I am able to include additional controls that are not typically included in social science surveys and may allow me to better control for individual heterogeneity in my regression models. Specifically, I include indicators for Catholic religion, living with both biological parents, maternal and paternal years of education (entered separately and linearly), access to educational materials in the home (separate indicators for a library card, magazines, and newspapers), living in a rural area, and speaking a language other than English in the home in all regression models. These variables are asked in the 1979 round and pertain to the time respondents are 14 years of age. Lastly I include the number of years (entered linearly) between the school-leaving period and the period in which access to employer-sponsored health insurance is measured. This variable proxies for experience in the labor market. I do not include variables that are potentially influenced by leaving school in an economic downturn (e.g., wages measured at the time information on access to employersponsored health insurance is collected) to avoid bias from over-controlling (Angrist and Pischke 2009) $)^{6}$.

I include indicators for missing covariates and assign missing observations the sample mean (continuous) or mode (binary) in the regression models. Results are robust if I employ listwise deletion and estimate regression models on the sample with complete information.

The AFQT, my proxy for ability, is a multiple choice test that it utilized by the U.S. Military to determine qualification for enlistment in the U.S. Armed Forces. It is commonly utilized within the economics literature to proxy ability (Heckman et al. 2006). The test measures knowledge and skill in 10 areas: general science, arithmetic reasoning, word knowledge, paragraph comprehension, numerical operations, coding speed, auto and shop information, mathematics knowledge, mechanical comprehension, and 
electronics information. The score is converted into a percentile by NLSY79 administrators, thus an 89 implies that the test-taker out-performed $89 \%$ of the sample. NLSY79 respondents were administered the AFQT in the 1981 survey at 16 to 24 years. To account for differences in maturity and schooling that may vary with age, I follow Kahn (2010) and age-standardize the AFQT score for individual $i$ in age group $g$ (16 to 24 years) with the following formula: $\left(A F Q T_{i g}-\overline{A F Q T}_{g}\right) / S D_{g}$.

In addition to controls for individual heterogeneity, I also control for time-varying school-leaving state variables that may influence both the probability of access to employer-sponsored health insurance and leaving school in an economic downturn. In particular I include: 1 ) the proportion of the working age (23 to 62 years) population in a white collar job (Morefield et al. 2012) from the Annual Social and Economic Supplement to the Current Population Survey (fringe benefits such as health insurance are more common in white collar than blue or pink collar jobs) ${ }^{7}, 2$ ) the number of state health insurance mandates for services, providers, and covered individuals (BlueCross BlueShield Association 2004) (mandates may reduce the probability of access to employer-sponsored health insurance as they increase the cost to employers of providing health insurance (Jensen and Morrisey 1999)), 3) the average value of Medicaid coverage for a family of four that receives assistance from Aid to Dependent Families ${ }^{8}$ (this variable proxies the generosity of public health insurance, an alternative to employer-sponsored health insurance for those who are eligible), and 4) total state and local expenditures on hospitals and health (this variable proxies public sentiment towards and funding for health within the school-leaving state) from the U.S. Bureau of the Census 9 .

\subsection{Empirical model}

Equation (1) presents the regression model I utilize to the estimate the persistent effects of leaving school in an economic downturn on access to employer-sponsored health insurance. The unit of observation in this regression model is a report of access to employer-sponsored health insurance in NLSY79 round $r$ by worker $i$ who left school in school-leaving state $s$ in school-leaving year $t$ :

$$
I_{r i s t}=\alpha_{0}+\alpha_{1} U_{r s t}+\alpha_{2} U_{r s t} * T_{r i s t}+\alpha_{3} T_{r i s t}+\alpha_{4}^{\prime} X_{i s t}+\alpha_{5}^{\prime} P_{r s t}+\alpha_{6}^{\prime} S_{s}+\alpha_{7}^{\prime} D_{t}+\varepsilon_{r i s t}
$$

$I_{\text {rist }}$ is an indicator for access to employer-sponsored health insurance in NLSY79 round $r$ for individual $i$ in school-leaving state $s$ school-leaving year $t$. $U_{r s t}$ is the state unemployment rate in school-leaving state $s$ and school-leaving year $t$, this variable is fixed across NLSY79 rounds for any respondent. $T_{\text {rist }}$ is the number of years since school-leaving (entered linearly). This variable proxies a worker's potential labor market experience and varies across rounds within a worker. The interaction between $U_{r s t}$ and $T_{\text {rist }}$ allows the relationship between the school-leaving state unemployment rate and access to employer-sponsored health insurance to vary (i.e., either expand or compress) across time. $X_{i s t}$ is a vector of personal characteristics described in Section 3.4, these variables do not vary across NLSY79 rounds within respondent. $P_{r s t}$ is a vector of timevarying school-leaving state policies and characteristics outlined in Section 3.4. $S_{s}$ and $D_{t}$ are vectors of school-leaving state and year fixed effects. Inclusion of the school- 
leaving state fixed effects implies that I utilize within school-leaving state variation in unemployment rates to identify health insurance effects. These fixed effects control for time invariant and difficult-to-observe between school-leaving state differences. In Section 5.3 I estimate an alternative specification that accounts for both time-invariant and time-varying difficult-to-observe variables. Lastly, $\varepsilon_{\text {rist }}$ is the error term.

I utilize a linear probability model and estimate equations separately by sex given different labor market participation patterns between men and women (Blau and Kahn 2007). I apply NLSY79 sample weights to account for survey design and attrition from the NLSY79 and cluster standard errors around the school-leaving state to account for correlated errors.

Identification of Equation (1) relies on the assumption that the school-leaving state unemployment rate is uncorrelated with the error term in Equation (1) after I condition on school-leaving state and personal characteristics, and various fixed effects. An obvious concern is that the time or location of school-leaving is endogenous to the unemployment rate (Kahn 2010; Kondo 2007; Maclean 2013b; Oreopoulos et al. 2012; Oyer 2006, 2008). School-leavers may engage in endogenous sorting to avoid leaving school in an economic downturn. Endogenous sorting may entail altering the time (e.g., enrolling in additional schooling, dropping out) or location (e.g., moving to a stronger labor market) of school-leaving.

Signing the bias attributable to endogenous sorting is difficult ex ante. School-leavers who avoid economic downturns may have unobservable characteristics (e.g., forethought, understanding of business cycles, access to financial resources) that permit avoidance behavior. Alternatively, only the most capable and hard-working individuals may be willing to leave school in an economic downturn as they know that their abilities will allow them to secure desirable jobs regardless of the economic conditions they face. Lastly, myopic individuals, or those who display hyperbolic discounting, may be willing to drop out of school before their education is complete to take advantage of an economic upturn ${ }^{10}$.

I estimate instrumental variable models to address this source of bias. I have three endogenous variables: the school-leaving state unemployment rate, the time since school-leaving (my proxy for potential experience), and the interaction between these two variables. Thus, I require at least three instrumental variables. To locate three IVs I follow the literature on the persistent effects of leaving school in an economic downturn (Kahn 2010; Kondo 2007; Maclean 2013b, 2014; Oreopoulos et al. 2012; Oyer 2006). First, I utilize state unemployment rate variation that is generated exogenously by birth year and early life residential decisions (put differently, these residential decisions are likely made by parents or caregivers rather than the school-leaver herself). I refer to this variable as the on time state unemployment rate. This variable captures the state unemployment rate a school-leaver would have faced had she not altered the time or location of school-leaving in response to contemporaneous economic conditions. For example, I assign a college graduate the annual state unemployment rate in the year she turned 22 (modal school-leaving age for college graduates in my sample) in the state of residence at age 14. I make comparable assignments for all educational levels. I delete respondents who did not reside in the U.S. at age 14 as I cannot match them to an age 14 state of residence. I use historical compulsory schooling laws (Acemoglu et al. 2001) to calculate school start dates. School-starting 
date information allows me to accurately predict the year in which the respondent would have left school if she did not engage in endogenous sorting. This instrument assumes that respondents follow normal progression through school (i.e., they do not repeat or skip grades) ${ }^{11}$.

Second, I take the difference between the modal age of school-leaving for the respondent's level of education at school-leaving and respondent age in the survey round access to employer-sponsored health insurance is collected. I refer to this variable as on time years since school-leaving. For example, if a respondent left school with a college degree and I measure her access to employer-sponsored health insurance at age 40 , the on time years since school-leaving IV takes the value of $18(40-22=18$, modal school-leaving age for someone who left school with a college degree). Third, I interact the on time state unemployment rate and the on time years since school-leaving. I refer to this variable as the interaction. This process provides three IVs. I use 2SLS to instrument for all endogenous variables simultaneously ${ }^{12}$.

\section{Results}

\subsection{Sample characteristics}

Summary statistics are reported in Table 2. $75 \%$ of men and $72 \%$ of women report access to employer-sponsored health insurance. The average state unemployment rate at school-leaving is 7.47 among men and 7.43 among women. The mean schoolleaving year for both men and women is 1980, and the average number of years since school-leaving (my proxy for labor market experience) is 14. Respondents left school with 13 years of education at age 19 on average. 50\% of workers are employed in a white collar job in the school-leaving state among men and women. The average number of private health insurance mandates, Medicaid expenditure for a family of four, and expenditures on health and hospitals in the school-leaving state is 8.21, \$229, \$2.24 million among men and 8.06, \$222, and \$2.18 million among women. Personal characteristics are consistent with an older cohort such as the NLSY79.

\subsection{OLS regression results}

Table 3 reports selected OLS estimates of the effect of leaving school in an economic downturn on access to employer-sponsored health insurance.

My findings suggest that leaving school in an economic downturn depresses the probability that a worker will have access to employer-sponsored health insurance and this effect is persistent. The effects are stronger for men than women in terms of both their magnitude and statistical significance. This pattern of results is consistent with much of the previous literature on the career effects of leaving school in an economic downturn. In particular, among men a 1 percentage point increase in the schoolleaving state unemployment rate leads to a 1.3 percentage point $(1.7 \%)$ reduction in the probability of having access to employer-sponsored health insurance. Considering the interaction term, which is positive in sign and statistically significant $(p \leq 0.01)$, the effect dissipates over time but remains statistically distinguishable from zero for roughly 22 years after school-leaving $(p \leq 0.01)$. At the sample mean number of years since schoolleaving (14.0) a 1 percentage point increase in the school-leaving state unemployment rate leads to a 0.41 percentage point $(0.55 \%)$ reduction in the probability of access 
Table 2 Summary statistics: NLSY79

\begin{tabular}{|c|c|c|}
\hline & Men & Women \\
\hline & Sample proportion/mean & Sample proportion/mean \\
\hline Employer-sponsored health insurance & 0.75 & 0.72 \\
\hline \multicolumn{3}{|l|}{ School-leaving variables } \\
\hline School-leaving state unemployment rate & 7.47 & 7.43 \\
\hline School-leaving year & 1980.5 & 1980.3 \\
\hline Years since school-leaving & 14.0 & 14.4 \\
\hline Years of education at school-leaving & 12.9 & 13.1 \\
\hline Age at school-leaving & 19.1 & 18.9 \\
\hline Proportion of workers in white collar job & 0.50 & 0.50 \\
\hline Number of private health insurance mandates & 8.21 & 8.06 \\
\hline Average Medicaid expenditure for a family of four & $\$ 229.4$ & $\$ 222.3$ \\
\hline Total expenditures on health and hospitals (millions) & $\$ 2.24$ & $\$ 2.18$ \\
\hline \multicolumn{3}{|l|}{ Personal characteristics } \\
\hline White & 0.84 & 0.82 \\
\hline African American & 0.12 & 0.13 \\
\hline Hispanic & 0.042 & 0.043 \\
\hline AFQT score & 51.3 & 50.8 \\
\hline Age-adjusted AFQT score & 0.40 & 0.38 \\
\hline Catholic religion at age 14 & 0.32 & 0.31 \\
\hline Live with both biological parents at age 14 & 0.78 & 0.77 \\
\hline Mother's years of education & 11.9 & 11.8 \\
\hline Father's years of education & 12.2 & 12.0 \\
\hline Library card in home at age 14 & 0.75 & 0.79 \\
\hline Magazines in home at age 14 & 0.70 & 0.70 \\
\hline Newspapers in home at age 14 & 0.87 & 0.85 \\
\hline Live in rural area at age 14 & 0.23 & 0.23 \\
\hline Speak non-English language in home at age 14 & 0.10 & 0.10 \\
\hline N & 57,827 & 56,862 \\
\hline
\end{tabular}

Notes: NLSY79 sample weights applied.

Table 3 Effect of leaving school in an economic downturn on access to employer-sponsored health insurance: OLS model

\begin{tabular}{lcr}
\hline & Men & Women \\
\hline Sample proportion & 0.75 & 0.72 \\
School-leaving state unemployment rate & $-0.0130^{* * *}(0.0042)$ & $0.0051(0.0052)$ \\
Interaction with time since school-leaving & $0.0006^{* * *}(0.0002)$ & $0.0001(0.0001)$ \\
Marginal effect estimated at the mean years & $-0.0041^{* *}(0.0020)$ & $0.0065^{* * *}(0.0020)$ \\
since school-leaving & 57,827 & 56,862 \\
$\mathrm{~N}$ & & 5
\end{tabular}

Notes: NLSY79 sample weights applied. All models estimated with a linear probability model and adjust for personal characteristics, and school-leaving state and year fixed effects. Standard errors are clustered around the school-leaving state and are reported in parentheses. The mean number of years since school-leaving is 14.0 among men and 14.4 among women. The standard error on the marginal effect estimated at the mean years since school-leaving is calculated with a parametric bootstrap using 1,000 repetitions.

$*^{* * *} ;{ }^{* *} ;{ }^{*}=$ Statistically significant at the $1 \% ; 5 \% ; 10 \%$ level. 
to employer-sponsored health insurance $(p \leq 0.50)$. I calculate the standard error on the marginal effect estimated at the mean using a parametric bootstrap with 1,000 repetitions.

Turning to women, I find no strong evidence that access to employer-sponsored health insurance is impacted by economic conditions at school-leaving: the coefficient on the state unemployment rate carries a positive sign but is an order of magnitude smaller than the coefficient estimated for men and is statistically indistinguishable from zero. Somewhat surprisingly, the marginal effect estimated at the mean years since school leaving is both positive and statistically distinguishable from zero. However, given that neither the main effect nor the interaction is statistically distinguishable from zero I do not consider this strong evidence.

\subsection{Instrumental variables regression results}

The key empirical challenge in this study is bias from endogenous sorting. To address this potential source of bias, I estimate two-stage least squares utilizing the instruments detailed in Section 3.5. Because of the endogenous sorting concerns, I view the results generated in the IV models as more reliable than those generated in the OLS models as the IV models will generate consistent estimates regardless of endogeneity in the schoolleaving variables. Before proceeding to the IV analysis I first provide some suggestive evidence on the magnitude of potential endogenous sorting of two forms, alternating educational attainment at school-leaving and moving to a stronger labor market, in my sample.

If members of my sample are avoiding leaving school in an economic downturn we might expect that cohort (i.e., the number of individuals who left school in a particular year) size will be smaller in high unemployment school-leaving years (1976 to 1996 in my sample). I first compare state cohort size with the state unemployment rate in a simple OLS regression. The majority (over 90\%) of my sample left school between the ages of 16 and 24 years, and for this exercise I focus on this age range. I first estimate the total number of school-levers in a given state/year using the NLSY79 sample weights. I then normalize the number of school-leavers in a given state/year by the number of potential school-leavers in that state/year. To do so, I use single year population (ages 16 to 24 years) estimates and the proportion of age-relevant individuals currently enrolled in school (i.e., the population at risk for school-leaving) using data from the 1970, 1980, and 1990 U.S. Censuses ${ }^{13}$. The findings are reported in Figure 2, the unit of observation is a school-leaving state/year pair. I also report the linear prediction on the graph, which has a positive slope but is statistically indistinguishable from zero $(\hat{\beta}=0.0045$; standard error $=0.0030)$. However, including school-leaving state and year fixed effects in the regression changes the sign $(\hat{\beta}=-0.0024)$ and the estimate remains indistinguishable from zero (standard error $=0.0041$ ). Although this evidence is purely descriptive, it does not support the hypothesis that individuals avoid leaving school in a downturn by remaining in school or dropping out.

I next provide some evidence on a second form of endogenous sorting: moving to a stronger labor market. Table 4 reports results from regressions of a past year acrossstate move on the lagged state unemployment rate among 14 to 30 years (the youngest members of the NLSY79 cohort are 14 years in 1979) old men and women. I chose age 30 as the cut-off to focus on observations of school-leaving age (results are not sensitive to using younger and older age cut-offs). I construct an indicator for a past year across 


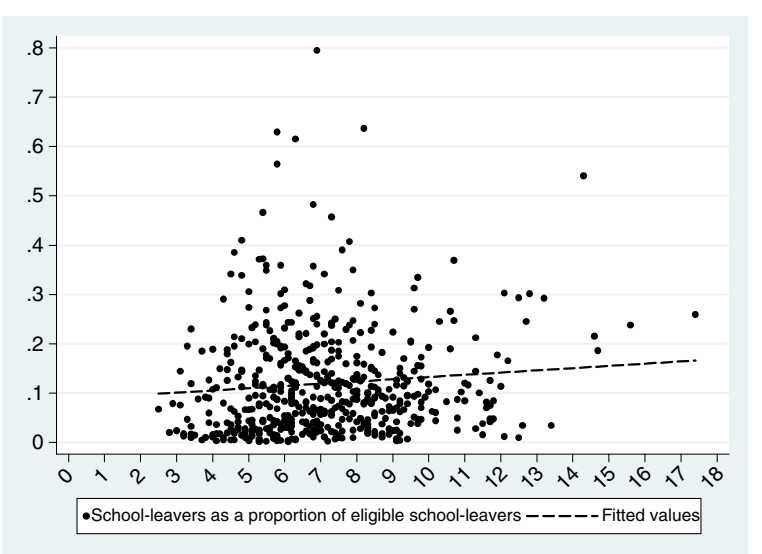

Figure 2 School-leavers as a proportion of eligible school-leavers vs. average annual state unemployment rates. Notes: The unit of observation is a school-leaving state in a year ( $N=517)$. A cohort is defined as the number of school-leavers in the NLSY79 who left school in the same year/year. Sources: School-leaving cohort size: NLSY79. Eligible school-leaving cohort size: U.S. Census. Annual state unemployment rate: Bureau of Labor Statistics Local Area Unemployment Statistics.

state move that takes the value of one if the state of residence in year $t$ is not equal to the state of residence in year $t-1$, and zero otherwise. I utilize a linear probability model, and control for personal characteristics described in Section 3.4 (age; race/ethnicity; years of education; a quadratic in the age-adjusted AFQT score; family background as measured Catholic religion, family structure, maternal and paternal years of education, access to educational materials, rural residence, and non-English language spoken in the home; and indicators for missing information), and lagged state and year fixed effect. I apply NLSY79 sample weights and cluster standard errors around the lagged state.

$6 \%$ of both men and women ages 14 to 30 years report a past year across-state move. I find evidence that individuals in my sample are less likely to move in economic downturns: a 1 percentage point increase in the lagged state unemployment rates is associated with a 0.9 (1.0) percentage point reduction in the probability of moving among men (women) $(p \leq 0.05)$. My data do not allow me to unpack the mechanisms behind these findings, but on average it may be that economic downturns constrain would-be movers in my sample perhaps through the inability to sell a home or to afford moving-related costs.

My analyses of endogenous sorting do not provide strong evidence of these behaviors in my sample. However, my checks are simple and likely do not capture all forms of endogenous sorting. Thus, I may not be able uncover endogenous sorting in the data. For this reason, I proceed with the IV analysis to more rigorously address bias attributable to these behaviors.

Table 4 Effect of the lagged state unemployment rate on past year across-state moves among NLSY79 respondents 14 to 30 years: Test of endogenous sorting

\begin{tabular}{lcc}
\hline & Men & Women \\
\hline Sample proportion & 0.06 & 0.06 \\
School-leaving state unemployment rate & $-0.0087^{* *}(0.0040)$ & $-0.0096^{* *}(0.0038)$ \\
N & 50,902 & 53,817
\end{tabular}

Notes: NLSY79 sample weights applied. All models estimated with a linear probability model and adjust for personal characteristics, and lagged state and year fixed effects. Standard errors are clustered around the lagged state and are reported in parentheses.

$*^{* * *} ;{ }^{* *} ;{ }^{*}=$ Statistically significant at the $1 \% ; 5 \% ; 10 \%$ level. 
IVs must predict the endogenous regressors to consistently estimate a local average treatment effect for compliers ${ }^{14}$. Table 5 presents selected results from first stage regressions: each of the endogenous variables is regressed on the excluded and included instruments using OLS. For brevity I report coefficient estimates for the excluded instruments only, but full results are available on request. The excluded instruments are strong predictors of the endogenous variables. For example, in the first stage regression of the school-leaving state unemployment rate the $F$-statistic of the joint significance of the 3 excluded instruments is 82 in the male sample and 134 in the female sample, above the minimum standard of 10 (Stock et al. 2002).

In the presence of heterogeneous treatment effects instrumental variable models estimate a local average treatment (LATE) for those individuals who comply with the IVs (Imbens and Angrist 1994). If there is homogeneity in treatment effects, then IV models can estimate an average treatment effect (Wooldridge 2010). Understanding what type of individual complies with my selected IVs is important for establishing whether or not these individuals represent an informative group to study and the generalizability of my findings to the broader population.

The type of individual who complies with my instruments is the type of individual who does not engage in endogenous sorting. What type of individual engages (or does not engage) in endogenous sorting is ex ante ambiguous as the compliers may conceptually represent a more or less advantaged group. I next compare personal characteristics of compliers and non-compliers to provide some empirical evidence

Table 5 Selected first stage regression results: Tests of instrumental variable power

\begin{tabular}{|c|c|c|}
\hline & Men & Women \\
\hline \multicolumn{3}{|c|}{ Endogenous variable: School-leaving state unemployment rate } \\
\hline Sample mean & 7.47 & 7.43 \\
\hline On time school-leaving state unemployment rate & $0.7414^{* * *}(0.0485)$ & $0.7959^{* * *}(0.0403)$ \\
\hline On time years since school-leaving & $0.0090^{* *}(0.0043)$ & $0.0160^{* * *}(0.0058)$ \\
\hline Interaction & $0.0004(0.0006)$ & $-0.0011(0.0007)$ \\
\hline F-statistic of joint IV significance ( $p$-value) & $81.96(0.0000)$ & $134.25(0.0000)$ \\
\hline \multicolumn{3}{|l|}{ Endogenous variable: Time since school-leaving } \\
\hline Sample mean & 1980.5 & 1980.3 \\
\hline On time school-leaving state unemployment rate & $-0.0020(0.0150)$ & $-0.0032(0.0132)$ \\
\hline On time years since school-leaving & $0.9877^{* * *}(0.0035)$ & $0.9882^{* * *}(0.0033)$ \\
\hline Interaction & $-0.0000(0.0003)$ & $-0.0000(0.0003)$ \\
\hline F-statistic of joint IV significance ( $p$-value) & $38,136.83(0.0000)$ & $57,980.98(0.0000)$ \\
\hline \multicolumn{3}{|c|}{$\begin{array}{l}\text { Endogenous variable: School-leaving state unemployment } \\
\text { rate*time since school-leaving }\end{array}$} \\
\hline Sample mean & 106.27 & 104.15 \\
\hline On time school-leaving state unemployment rate & $-0.2332(0.4699)$ & $0.6619(0.6439)$ \\
\hline On time years since school-leaving & $1.7647^{* * *}(0.2126)$ & $1.9071^{* * *}(0.2013)$ \\
\hline Interaction & $0.7596^{* * *}(0.0345)$ & $0.7269^{* * *}(0.0296)$ \\
\hline F-statistic of joint IV significance ( $p$-value) & $2,750.53(0.0000)$ & $1,456.99(0.0000)$ \\
\hline N & 57,827 & 56,862 \\
\hline
\end{tabular}


on the type of respondent who complies with my selected instruments. I refer to those individuals whose on time school-leaving year matches their actual school-leaving year, and their state of residence at age 14 matches their state of residence at actual schoolleaving, as compliers to the on time instrument. Table 6 presents personal characteristics included in Equation (1) for the on time instrument compliers and non-compliers.

On average, the compliers to the instrument are likely less advantaged than the noncompliers. For example, they left school in states with a lower prevalence of white collar workers, fewer private health insurance mandates, lower average Medicaid expenditures for a family of four, and lower state expenditures on health and hospitals. Moreover, the compliers left school with fewer years of education at younger ages, have lower ageadjusted AFQT scores, have less educated parents, and have otherwise less advantaged family backgrounds (e.g., at age 14 they have less access to cultural materials in the home and are more likely to live in a rural area) than the non-compliers. Moreover, these differences are generally statistically different from zero. Compliers are less likely to be an ethnic minority and speak a non-English language in the home at age 14, however.

Table 6 Characteristics of compliers and non-compliers to the on time instrumental variable

\begin{tabular}{|c|c|c|c|}
\hline & Complier* & Non-complier* & Difference ( $p$-value) \\
\hline \multicolumn{4}{|l|}{ School-leaving state characteristics } \\
\hline Proportion of workers in white collar job & 0.49 & 0.50 & 0.0000 \\
\hline Number of private health insurance mandates & 7.51 & 8.36 & 0.0000 \\
\hline Average Medicaid expenditure for a family of four & $\$ 222.6$ & $\$ 227.2$ & 0.0000 \\
\hline Total expenditures on health and hospitals (millions) & $\$ 1.98$ & $\$ 2.29$ & 0.0000 \\
\hline \multicolumn{4}{|l|}{ Personal characteristics } \\
\hline Age at school-leaving & 18.7 & 19.1 & 0.0000 \\
\hline Year of school-leaving & 1980.0 & 1980.6 & 0.0000 \\
\hline Years of education at school-leaving & 12.7 & 13.1 & 0.0000 \\
\hline Time since school-leaving & 14.5 & 14.1 & 0.0000 \\
\hline Male & 0.53 & 0.50 & 0.0000 \\
\hline Female & 0.47 & 0.50 & 0.0000 \\
\hline White & 0.82 & 0.83 & 0.0000 \\
\hline African American & 0.14 & 0.12 & 0.0000 \\
\hline Hispanic & 0.040 & 0.043 & 0.0001 \\
\hline Age-adjusted AFQT score & 0.24 & 0.44 & 0.0000 \\
\hline Catholic religion at age 14 & 0.31 & 0.32 & 0.0000 \\
\hline Live with both biological parents at age 14 & 0.76 & 0.78 & 0.0000 \\
\hline Mother's years of education & 11.6 & 11.9 & 0.0000 \\
\hline Father's years of education & 11.7 & 12.2 & 0.0000 \\
\hline Library card in home at age 14 & 0.75 & 0.78 & 0.0000 \\
\hline Magazines in home at age 14 & 0.67 & 0.71 & 0.0000 \\
\hline Newspapers in home at age 14 & 0.86 & 0.86 & 0.0000 \\
\hline Live in rural area at age 14 & 0.24 & 0.23 & 0.0000 \\
\hline Speak non-English language in home at age 14 & 0.097 & 0.10 & 0.0013 \\
\hline N & 30,967 & 83,722 & \\
\hline
\end{tabular}

*A complier to the on time school-leaving state unemployment rate is defined as a respondent whose actual year and state of school leaving are equal to year and state of school-leaving predicted by the on time state unemployment rate. 
Table 7 reports selected results from the instrumental variables models. The relationships identified in OLS regressions remain after instrumenting for the school-leaving state unemployment rate. A 1 percentage point increase in the school-leaving state unemployment rate leads to a 1.7 percentage point $(2.2 \%)$ reduction in the probability of having access to employer-sponsored health insurance $(p \leq 0.01)$. Although the effect dissipates over time it is statistically distinguishable from zero 18 years after schoolleaving $(p \leq 0.01)$. At the sample mean number of years since school-leaving (14.0 years) a 1 percentage point increase in the school-leaving state unemployment rate leads to a 0.5 percentage point $(0.6 \%)$ lower probability of access to employer-sponsored health insurance $(p \leq 0.10)$. Thus, the findings generated in the IV model for men are highly comparable to those generated in the OLS model.

Coefficient estimates for the main effect and interaction are small and statistically indistinguishable from zero among women. However, as in the OLS regressions, the marginal effect estimated at the mean is positive and statistically distinguishable from zero.

\section{Robustness checks and extensions}

In this section I assess the robustness of my findings to alternative proxies of economic conditions at school-leaving and controls to school-leaving state characteristics, and I conduct several extensions to the core analyses. For brevity I present results from the IV models unless otherwise indicated. OLS estimates are comparable and available on request.

\subsection{Alternative measures of economic conditions at school-leaving}

In my core analyses I proxy economic conditions with the annual seasonally adjusted state unemployment rate. I next re-estimate models using the state seasonally unadjusted unemployment rates in June (modal school-leaving month for high school graduates in my sample) and May (modal school-leaving month for college graduates in my sample) ${ }^{15}$. Utilizing unemployment rates from these particular months may better capture economic conditions at school-leaving. The results are reported in panels 1 and 2 of Additional file 3 and are consistent with results generated in the core model that utilizes the annual rate ${ }^{16}$.

Table 7 Effect of leaving school in an economic downturn on access to employersponsored health insurance: IV model

\begin{tabular}{lcr}
\hline & Men & Women \\
\hline Sample proportion & 0.75 & 0.72 \\
School-leaving state unemployment rate & $-0.0165^{* * *}(0.0061)$ & $0.0059(0.0070)$ \\
Interaction with time since school- leaving & $0.0009^{* * *}(0.0002)$ & $0.0000(0.0002)$ \\
Marginal effect estimated at the mean years since school-leaving & $-0.0045^{*}(0.0025)$ & $0.0066^{* *}(0.0027)$ \\
N & 57,827 & 56,862 \\
\hline
\end{tabular}

Notes: All models estimated with two stage least squares and apply NLSY79 sample weights. Regressions adjust for personal characteristics, state of residence at age 14 fixed effects, and on time year fixed effects. Standard errors are clustered by state of residence at age 14 and are reported in parentheses. The mean number of years since schoolleaving is 14.0 among men and 14.4 among women. The standard error on the marginal effect at the mean years since school-leaving is calculated with a parametric bootstrap using 1,000 repetitions.

***; **; * Statistically significant at the $1 \% ; 5 \% ; 10 \%$ level. 


\subsection{Alternative controls for school-leaving state heterogeneity}

The models presented thus far include state fixed effects and control for unobservable time invariant state characteristics, and state labor market characteristics and policies (proportion of work force in a white collar job, number of private health insurance mandates, average value of Medicaid for a family of four, and total expenditures on health and hospitals). However, if there are additional state-level characteristics that vary over time this specification may suffer from omitted variable bias. Because my sample left school between 1976 and 1996, a period that spans 21 years, we might expect change in important unobservable state characteristics. To address bias from such unobservables I estimate regression models that include state-specific linear time trends (put differently, I interact a linear time with the school-leaving state fixed effects) and control for difficult to observe time-variant school-leaving state characteristics. Results are reported in Additional file 3 (panel 3) do not differ appreciably from those estimated in the core models.

\subsection{Alternative forms of non-monetary compensation}

Next, I consider whether leaving school in an economic downturn influences access to a second non-monetary form of compensation: employer-sponsored life insurance. Specifically, I replace the employer-sponsored health insurance indicator with an indicator for access to employer-sponsored life insurance in Equation (1). Consistent with health insurance studied in the main sections of this manuscript, this variable is available in all years of the NLSY79 with the exception of 1981. I also construct a measure of access to neither employer-sponsored health nor life insurance. These two measures of access to employer-sponsored benefits are subject to the limitations noted in Section 3.2 for the health insurance variable.

Results are reported in Panels 1 and 2 of Additional file 4. 64\% (24\%) of men and $62 \%(27 \%)$ of women in my sample have access to employer-sponsored health insurance (do not have access to either employer-sponsored benefit). The regressions suggest that men (but not women) who leave school in an economic downturn are less likely to have access to employer-sponsored benefits and are more likely to have access to neither health nor life insurance through their employer, and this effect is persistent. For example, in the IV model a 1 percentage point increase in the schoolleaving state unemployment rate leads to a 1.9 percentage point (3.0\%) reduction in the probability of having access to employer-sponsored life insurance and this effect is statistically distinguishable from zero for roughly 19 years after school-leaving $(p \leq 0.05)$. At the sample mean years since school-leaving among men (14.0 years), a 1 percentage point increase in the school-leaving state unemployment rate reduces the probability that a male respondent has access to employer-sponsored life insurance by 0.5 percentage point $(0.8 \%)$. Turning next to women, the coefficient estimates on the main effect are negative but small in magnitude and indistinguishable from zero for both outcomes. However, the marginal effect estimated at the mean for access to neither employer-sponsored benefit is negative and statistically indistinguishable from zero. These findings suggest that leaving school in an economic downturn persistently reduces male, but not female, workers' ability to access non-monetary forms of compensation beyond health insurance. 


\subsection{Potential explanations for sex differences}

I find that men's, but not women's, access to employer-sponsored health insurance is influenced by the economic conditions at school-leaving. I next attempt to shed some light on potential explanations for this difference in findings. In particular, I examine the source of health insurance through a series of questions administered in the 1989 through 2010 surveys (with the exception of the 1991 survey). These questions are asked separately from the access to employer-sponsored health insurance variables and measure some combination of insurance access and take-up, and are thus not entirely comparable with results presented earlier which examine exclusively access to employer-sponsored health insurance.

I model the probability that the source of the health insurance is 1) the respondents' current or former employer and 2) the spouse's (or partner's) current or former employer $^{17}$. Further, I look to see if the respondent is married and the absolute difference between respondent and spouse/partner age at the time of the survey (this latter variable is not defined for respondents who are not married or cohabitating). If women who leave school in an economic downturn are disproportionately marrying older (or perhaps younger) men, then they may receive health insurance through their spouse and take jobs that do not offer this benefit. Such behavior could explain my core findings. These marriage variables are collected in all rounds of the NLSY79. To this end, I construct a set of binary variables for the two sources of health insurance and married (vs. unmarried), and a linear measure the absolute difference between respondent and spouse/partner age ${ }^{18}$. Results are reported in Panels 1 to 4 of Additional file 5 .

I find little evidence that that respondents who left school in an economic downturn are more or less likely to have insurance through their own employer or their spouse's/ partner's employer. Although some of the marginal effects estimated at the mean are statistically distinguishable from zero, none of the main effects or interaction terms are precisely estimated. The coefficient on the school-leaving state unemployment rate in the marriage regressions are imprecise (although the marginal effects estimated at the mean are distinguishable from zero and suggest that both men and women who leave school in an economic downturn are less likely to be married). Moreover, men (but not women) who leave school in a downturn marry who are on average slightly discordant in age. In general, these analyses do not shed much light on why the effects I observe for health insurance are stronger for men than women.

\subsection{Use of public health insurance}

If school-leavers do not have access to employer-sponsored health insurance they may instead take up public health insurance and place a direct financial burden on the American tax payer. In next consider this possibility by modeling the probability of reporting Medicaid, a joint federal and state health insurance program that covered 55 million individuals a cost of $\$ 408$ billion annually in 2011 (Centers for Medicare and Medicaid Services 2013), as the source of health insurance. I next test how use of Medicaid and other government health insurance is influenced by leaving school in an economic downturn. To define this variable, I again utilize a series of questions administered in the 1989 through 2010 surveys (with the exception of the 1991 
survey) on the source of health insurance. Results from this analysis are reported Panel 5 of Additional file 5. I do not observe substantial evidence that men and women who leave school in an economic downturn are more likely to take up public health insurance as measured in the NLSY79, although the coefficients are positive they are imprecisely estimated among both men and women. However, the first year in which Medicaid information is available is 1989 when NLSY79 respondents are between the ages of 24 and 32. Medicaid eligibility is closely linked with the presence of children for many. For example, women who would not otherwise be eligible for Medicaid become eligible when they are pregnant. Thus, my inability to study younger women (those women who are more likely to become pregnant) may impede my ability to detect effects. Moreover, if income increases across the life course I will miss periods during which individuals (both men and women) have particularly low levels of income and are most likely to be eligible for Medicaid.

\subsection{Alternative specification for time since school-leaving}

In Equation (1) I interact the school-leaving state unemployment rate with the time since school-leaving. This specification imposes structure on the evolution of the relationship between leaving school in an economic downturn and access to employersponsored health insurance. I next estimate a more flexible model to study how leaving school in an economic downturn persistently influences access to employer-sponsored health insurance. Specifically, I re-estimate Equation (1) with an interaction between the school-leaving state unemployment rate and indicators for the time since school-leaving: 5 to 9 years, 10 to 14 years, 15 to 19 years, 20 to 24 years, 25 to 29 years, and 30 to 35 years (with 1 to 4 years as the omitted category). I chose to estimate only the OLS regression model as estimation of a comparable IV model requires that I instrument each interaction between the state unemployment at school-leaving and the time since school-leaving indicators, and likely asks too much of the data.

Results are reported in Additional file 6. The coefficients in this specification are highly statistically significant in the range of my data (i.e., up to 35 years after school-leaving) for men. The main effect is larger than the interaction effects through 25 to 29 years (with the exception of the 15 to 19 years). Among women the coefficients are all terms are positive and small in magnitude. They are generally statistically indistinguishable from zero, although interactions between the school-leaving state unemployment rate and the 20 to 24 and 30 to 35 years since school-leaving indicators are marginally statistically significant $(p \leq 0.10)$. Thus, these findings are broadly consistent with the core findings.

\section{Discussion}

In this study, I contribute new evidence to the literature on the career effects of leaving school in an economic downturn. Previous work has focused mainly on wages and earnings, occupational prestige, and likelihood of promotion. I document here that leaving school in an economic downturn also persistently reduces the probability of access to non-monetary forms of compensation as measured by employer-sponsored health and life insurance. My findings are driven mainly by men, and this is consistent with previous work that has identified stronger career effects of leaving school in an economic downturn for men than women. Specifically, in my preferred IV specification 
I find that a 1 percentage point increase in the school-leaving state unemployment rate leads to a $1.7 \%$ reduction in the probability of access to employer-sponsored health insurance among men. Although this effect dissipates across time, it is statistically distinguishable from zero 18 years after school-leaving.

It is perhaps surprising that my findings are observed only among men. While these sex differences are consistent with previous studies which identify larger career penalties attributable to leaving school in an economic downturn for men than women, it is potentially useful to think why I find few effects among women. My analysis of health insurance source (own employer, spouse/partner employer) and marriage outcomes does not offer additional insight. However, the latter null-findings are consistent with work by Kondo (2011). The author examines who economic conditions at marriage market entrance (defined in the main analyses as ages 18 to 20, and thus this stage of the life course may overlap with labor market entrance for some women) do not influence the probability of marriage at age 35 or spousal characteristics. Because health insurance is often provided to families, if a woman's spouse is less likely to have a job that offers health insurance the woman may attempt to obtain a job that does. My results do not show this type of behavior. However, there may be two types of women in the sample: 1) those who - because they left school in an economic downturn - are less likely to obtain a job that offers health insurance and 2) those who - because their spouse/partner left school in an economic downturn and was unable to obtain a job that offers health insurance - are more likely to hold a job that offers health insurance. These two types of women may net each other out in my regressions. Moreover, there may be selection into labor force participation among women, particularly in an older cohort such as the NLSY79 with lower female labor market participation. Perhaps only those women whose ability to access employer-sponsored health insurance is unaffected by economic conditions at school-leaving chose to enter the labor market and this behavior may mute effects. None of these speculations is particularly satisfactory and future research could consider this question more rigorously.

A potentially useful way to consider my findings is to ask what they imply in light of the introduction of the ACA. This legislation has the potential to transform the ways in which individuals obtain private health insurance coverage. In particular, it may reduce the probability that employers offer health insurance to employees (Emanuel 2014). The cohort I study, the NLSY79, did not have ready access to public health insurance and thus inability to access employer-sponsored health insurance left members of this cohort with the options of purchasing health insurance on the individual market or remaining uninsured and relying on emergency medical care. The ACA is predicted to provide access to health insurance to individuals and, in turn, prevent un-insurance. Thus, more recent cohorts of school-leavers will be at lower risk of un-insurance than members of the NLSY79. However, if there are differences in the quality of health insurance that is offered through the ACA in terms of generosity (e.g., copayments or deductibles) or ability to access medical services in a timely manner (e.g., overcrowding of public health insurance) relative to health insurance plans offered by employers, then future cohorts that leave school in an economic downturn may still face penalties in terms of access to health insurance relative to cohorts that left school in stronger economic conditions. Moreover, I show here that the penalty applies to a range of non-monetary forms of compensation (e.g., life insurance) which the ACA does 
not address and if workers who are unable to access employer-sponsored health insurance are more likely to take up public insurance this will have implications for public healthcare expenditures. Specifically, provisions of the ACA are expected to substantially increase eligibility for Medicaid and future cohorts of workers who leave school in a downturn will be better able to access this source of public health insurance.

Further, it is possible that employers are more concerned with the total cost of compensation than how compensation is split between wages and non-monetary benefits. Thus, a compensating differentials story suggests that a firm will trade off wages and non-monetary forms of compensation it offers to employees (Buchmueller et al. 2013; Currie and Madrian 1999; Gruber 1994). If employers chose not to offer health insurance in the post-ACA era they will have less ability to reduce health insurance offers as a form of compensation in downturns and may instead reduce wages, or other forms of non-monetary compensation, of school-leavers to a larger degree than estimated in previous studies.

An important limitation of this work is that the NLSY79 contains only one cohort and how well findings generalize to the broader population is unclear. In particular, female labor force participation rates have increased substantially since the NLSY79 sample left school. Because today's women may "look" more like NLSY79 men than NLSY79 women, we might expect that they will experience similar health insurance effects as I identify for NLSY79 men.

Although this study is not a policy analysis per se, the findings suggest that labor market or macroeconomic policies that counter the negative impacts of economic downturns may have previously unconsidered benefits. Rather than simply improving outcomes in the short run, developing effective policies to assist cohorts of workers entering the labor market in an economic downturn may have important and persistent benefits in terms of wages and other non-monetary forms of compensation (e.g., health insurance). Moreover, in terms of equity, such programs could dampen inter-cohort differences in access to employer-sponsored health insurance, wages, and other forms of compensation. Although it is beyond the scope of this study to provide specific policy recommendations future work in this area may be worthwhile. There is precedence for this type of government intervention: the Federal and state governments currently offer assistance to school-leavers during the school-to-work transition, and these programs could be expanded and/or fine-tuned during economic downturns.

\section{Conclusions}

In summary, this study provides new evidence on the persistent effects of leaving school in an economic downturn on non-monetary forms of compensation as measured by health and life insurance. Moreover, investigating the impact of leaving school in a downturn on other non-monetary forms of compensation may provide a broader picture of the full consequences.

\section{Endnotes}

${ }^{1}$ There is an important line of research examining the value of medical services (that is whether their use improves health outcomes) that I do not address in this study.

${ }^{2}$ Between 1979 and 1993 employer-sponsored health insurance information was collected only from the CPS job. 
${ }^{3}$ In 1979 employer-sponsored health insurance was collected from all respondents who reported some work outside the home, between 1980 and 1992 employersponsored health insurance was collected from respondents who worked 20 hours or more in their current or most recent job and were not self-employed, between 1993 and 2010 employer-sponsored health insurance information was collected from all respondents who reported some work.

${ }^{4}$ I drop respondents who left school after 1996 as a school-leaving state control variable, described in more detail later in the manuscript, is not available beyond 1996.

${ }^{5}$ Results are highly robust to using the seasonally adjusted state unemployment rate, however.

${ }^{6}$ Age and years of education at school-leaving, and the AFQT score are also potentially endogenous to the school-leaving state unemployment rate. However, results are highly robust if I exclude these covariates from the regression models.

${ }^{7}$ In particular, I follow Morefield et al. (2012) and classify the following Census three digit occupational codes as white collar: Professional Specialty \& Technical Occupations (43-235); Executive, Administrative, \& Managerial Occupations (3-37); Sales Occupations (243-85); Administrative Support Occupations (303-49, 353-4, 356-89); and Managers, Farms, Except Horticultural (475). In addition I classify Managers of Horticultural Specialty Farms (476) as white collar, this category is not classified by Morefield et al. (2012).

${ }^{8}$ This variable was collected by Dr. Elizabeth Peters through private data collection and is available through 1996.

${ }^{9}$ Data were provided through a private request from the U.S. Census Bureau.

${ }^{10} \mathrm{An}$ additional concern is measurement error in the school-leaving variables. There are at least two sources of measurement error in my study. First, I rely on self-reported year of school-leaving and these reports may contain error. Second, I utilize a measure of economic conditions at the state level. This variable may be a poor proxy for economic conditions if the salient labor market for school-leavers is the local (e.g., county or city) market. As noted earlier in the manuscript, the sign of measurement error inducted bias is difficult to sign (Bound et al. 2001).

${ }^{11}$ If respondents do not follow normal progression through their schooling then I will assign instrument values with some error. For example, if a college graduate skipped grade two she would, all else equal, graduate from college a year early. I would not account for this in my instrumental variable assignment and would instead assign her the state unemployment one year later than I should. Use of school starting age law should not lead to substantial bias as they are predetermined to school-leaving by many years by state legislatures.

${ }^{12}$ I do not estimate a form of forbidden regression with non-linear instrumental variables. Instead, I follow Wooldridge (2010) and apply the 2SLS formula directly.

${ }^{13}$ The U.S. Census provides inter-census year estimates for population by single year of age, but I must predict estimates of the population currently enrolled in school for inter-census years. To do so, I regress the relevant age population on state and year fixed effects, and state-specific linear time trends using OLS. I assign out of range predictions (i.e., either less than zero or greater than one) with the sample minimum or maximum values. The R-squared from this regression is 0.98 .

${ }^{14}$ Compliers in an instrumental variable framework are typically those individuals who change their behavior as a result of the intervention utilized as an IV. Here the 
compliers are those individuals whose behavior coincides with the predictions used as the instrumental variable.

${ }^{15}$ Results generated utilizing the seasonally adjusted June and May state unemployment rates are highly robust.

${ }^{16}$ The state unemployment rate is but one proxy for economic conditions and it has known limitations (e.g., the rate may be endogenous to the true economic conditions at workers may exit the labor market in economic downturns and re-enter when the economy rebounds). In unreported analyses, I utilize alternative proxies for economic conditions at school-leaving 1) the annual state employment-to-population ratio from the BLS and 2) the standardized state unemployment rate (specifically I standardize the state unemployment rate by subtracting the state-specific mean and dividing by the state-specific standard deviation between 1976 and 1996, the years in which my sample left school). The employment-to-population ratio is less sensitive to workers endogenously exiting and re-entering the labor market while deviations from period trends addresses differences in states' historic levels of unemployment that are not fully captured by the school-leaving state fixed effects. Findings from these alternative models are comparable with findings reported in the manuscript and are available on request.

${ }^{17}$ In all rounds I can separately identify whether the source of health insurance is the respondent's current employer; the respondent's former employer; the spouse's/partners' current employer; or the spouses'/partner's former employer. Exceptions are the 2002, 2004, and 2006 rounds, in which respondents are asked whether they receive health insurance through their own or their spouse's/partner's previous employer. For these years, I assume that the source is the respondent's former employer. Results are robust if I drop these rounds from the sample.

${ }^{18}$ I determine age of the spouse through questions regarding the spouse's year and month of birth. Because they are reported values, they are potentially vulnerable to measurement error.

\section{Additional files}

Additional file 1: Proportion of the NLSY79 sample reporting access to employer-sponsored health insurance by survey round. This table reports survey question wording for questions pertaining to employer-sponsored health insurance access, survey question universe for these questions, and the proportion of the analysis sample drawn from the NLSY79 that reports access to employer-sponsored health insurance by NLSY79 round based on author's calculations of the NLSY79.

Additional file 2: Proportion of the NLSY79 sample reporting access to employer-sponsored health insurance by age. This figure reports the proportion of the analysis sample drawn from the NLSY79 that reports access to employer-sponsored health insurance by NLSY79 age.

Additional file 3: Effect of leaving school in an economic downturn on access to employer-sponsored health insurance using alternative proxies for economic conditions and controls for between school-leaving state differences: IV model. This table reports IV regression results from various sensitivity checks.

Additional file 4: Effect of leaving school in an economic downturn on access to alternative employer-sponsored benefits: IV model. This table reports IV regression results from extensions to the core analysis.

Additional file 5: Effect of leaving school in an economic downturn on source of health insurance and marriage outcomes: IV model. This table reports IV regression results from extensions to the core analysis.

Additional file 6: Effect of leaving school in an economic downturn access to employer-sponsored health insurance using a non-parametric specification for time since school-leaving: OLS model. This table reports OLS regression results from an alternative specification. 


\section{Acknowledgements}

I would like to thank Yaa Akosa Antwi, Stefan Boes, Reginald Covington, David Neumark, Elizabeth Peters, Douglas Webber, and an anonymous referee. All errors are my own.

Disclaimer: This research was conducted with restricted access to Bureau of Labor Statistics (BLS) data. The views expressed here do not necessarily reflect the views of the BLS.

Responsible editor: David Neumark

Received: 7 March 2014 Accepted: 27 June 2014

Published: 09 Sep 2014

\section{References}

111th United States Congress (2010) The patient protection and affordable care act. Washington, DC

Acemoglu D, Angrist J, Bils M, Rouse CE (2001) How large are human-capital externalities? Evidence from compulsory schooling laws. NBER Macroecon Annu 2000 15:9-74

Angrist JD, Pischke J (2009) Mostly harmless econometrics: an empiricist's companion. Princeton University Press, Princeton, NJ

Beaudry P, DiNardo J (1991) The effect of implicit contracts on the movement of wages over the business cycle: evidence from micro data. J Polit Econ 99:665-688

Blau F, Kahn L (2007) Changes in the labor supply behavior of married women: 1980-2000. J Labor Econ 25:393-438

BlueCross BlueShield Association (2004) State legislative health care and insurance issues: 2004 survey of plans. BlueCross BlueShield Association, Chicago, IL

Bound J, Brown C, Mathiowetz N (2001) Chapter 59 measurement error in survey data. In: Heckman JJ, Leamer E (eds) Handbook of econometrics. Elsevier, Amsterdam, Netherlands, pp 3705-3843

Buchmueller T, Carey C, Levy HG (2013) Will employers drop health insurance coverage because of the affordable care act? Health Aff 32:1522-1530

Cawley J, Simon KI (2005) Health insurance coverage and the macroeconorny. J Health Econ 24:299-315

Cawley J, Moriya AS, Simon K (2013) The impact of the macroeconomy on health insurance coverage: evidence from the great recession. Health economics. http://onlinelibrary.wiley.com/doi/10.1002/hec.3011/full

Centers for Medicare and Medicaid Services (2013) National health expenditure projections 2012-2022. Centers for Medicare and Medicaid Services, Baltimore, MD

Chernew ME, Hirth RA, Cutler DM (2009) Increased spending on health care: long-term implications for the nation. Health Aff 28:1253-1255

Claxton G, Rae M, Panchal N, Damico A, Whitmore H, Bostick N, Kenward K (2013) Health benefits in 2013: moderate premium increases in employer-sponsored plans. Health Aff 32:1667-1676

Congressional Budget Office (2013) Updated budget projections: fiscal years 2013 to 2023. Congressional Budget Office, Washington, DC

Courtemanche CJ, Zapata D (2014) Does universal coverage improve health? the Massachusetts experience. Journal of Policy Analysis and Management 33:36-69

Currie J, Gruber J (1996) Health insurance eligibility, utilization of medical care, and child health. Q J Econ 111:431-466

Currie J, Madrian BC (1999) Chapter 50 health, health insurance and the labor market. In: Orley CA, David C (eds) Handbook of labor economics. Elsevier, Amsterdam, Netherlands, pp 3309-3416

Cutler D, Huang W, Lleras-Muney A (2014) When does education matter? The protective effect of education for cohorts graduating in bad times. National Bureau of Economic Research, Cambridge, MA

DeNavas-Walt C, Proctor B, Smith J (2013) Income, poverty, and health insurance coverage in the United States: 2012. In: Current population reports. U.S. Census Bureau, Washington, DC

Emanuel E (2014) Reinventing American health care: how the affordable care act will improve our terribly complex, blatantly unjust, outrageously expensive, grossly inefficient, error prone system. PublicAffairs, New York, NY

Finkelstein A, Taubman S, Wright B, Bernstein M, Gruber J, Newhouse JP, Allen H, Baicker K (2012) The Oregon Health Insurance Experiment: Evidence from the First Year. Quarterly Journal of Economics 127(3):1057-1106

Genda Y, Kondo A, Ohta S (2010) Long-term effects of a recession at labor market entry in Japan and the United States. J Hum Resour 45:157-196

Gross T, Notowidigdo MJ (2011) Health insurance and the consumer bankruptcy decision: evidence from expansions of Medicaid. J Public Econ 95:767-778

Grossman M (1972) On the concept of health capital and the demand for health. J Polit Econ 80:223-255

Gruber J (1994) The incidence of mandated maternity benefits. Am Econ Rev 84:622-641

Heckman JJ, Stixrud J, Urzua S (2006) The effects of cognitive and noncognitive abilities on labor market outcomes and social behavior. J Labor Econ 24:411-482

Hershbein BJ (2012) Graduating high school in a recession: work, education, and home production. In: The B.E. Journal of Economic Analysis \& Policy

Hessel P, Avendano M (2013) Are economic recessions at the time of leaving school associated with worse physical functioning in later life? Ann Epidemiol 23:708-715

Himmelstein DU, Thorne D, Warren E, Woolhandler S (2009) Medical bankruptcy in the United States, 2007: results of a national study. Am J Med 122:741-746

Hofmann B, Hohmeyer K (2014) The effect of the business cycle at college graduation on fertility

Imbens GW, Angrist JD (1994) Identification and estimation of local average treatment effects. Econometrica 62:467-475

Jensen GA, Morrisey MA (1999) Employer-sponsored health insurance and mandated benefit laws. Milbank Q 77:425-459

Kahn LB (2010) The long-term labor market consequences of graduating from college in a bad economy. Labour Econ 17:303-316

Kahn JR, Pearlin LI (2006) Financial strain over the life course and health among older adults. J Health Soc Behav 47:17-31 
Kaiser Family Foundation (2012) Health insurance market reforms: pre-existing condition exclusions. Menlo Park, CA Kondo A (2007) Differential effects of graduating during a recession across race and gender. In: Institute for social and economic research and policy working paper. Institute for Social and Economic Research and Policy, Essex, U.K

Kondo A (2011) Gender-specific labor market conditions and family formation. J Popul Econ 25:151-174

Kwon I, Milgrom EM, Hwang S (2010) Cohort effects in promotions and wages. J Hum Resour 45:772-808

Maclean JC (2013a) Does leaving school in an economic downturn persistently affect body weight? Evidence from panel data. University of Pennsylvania

Maclean JC (2013b) The health effects of leaving school in a bad economy. J Health Econ 32:951-964

Maclean JC (2014) The lasting effects of leaving school in an economic downturn on alcohol use. Industrial and Labor Relations Review Accepted

Maclean JC, Hill T (2013) Leaving school in an economic downturn and self-esteem across early and middle adulthood. University of Pennsylvania

Maclean JC, Covington R, Sikora A (2013) Leaving school in an economic downturn: Long-run effects on marriage and fertility. University of Pennsylvania

Marquis MS, Long SH (2001) Employer health insurance and local labor market conditions. Int J Health Care Finance Econ 1:273-292

Meyer BD, Wherry LR (2012) Saving teens: using a policy discontinuity to estimate the effects of Medicaid eligibility. NBER working series. National Bureau of Economic Research, Cambridge, MA

Morefield B, Ribar DC, Ruhm CJ (2012) Occupational status and health transitions. B E Journal of Economic Analysis \& Policy 11:8

National Bureau of Economic Research (2010) U.S. business cycle expansions and contractions. National Bureau of Economic Research, Cambridge, MA

Neumark D (2002) Youth labor markets in the United States: shopping around vs. staying put. Review of Economics and Statistics 84:462-482

Newhouse J (1993) Free for all. Harvard University Press, Cambridge, MA

Oreopoulos P, von Wachter T, Heisz A (2012) The short- and long-term career effects of graduating in a recession. American Economic Journal: Applied Economics 4:1-29

Oyer P (2006) Initial labor market conditions and long-term outcomes for economists. J Econ Perspect 20:143-160

Oyer P (2008) The making of an investment banker: stock market shocks, career choice, and lifetime income. J Financ 63:2601-2628

Schoar A, Zuo L (2011) Shaped by booms and busts: how the economy impacts CEO careers and management styles. In: NBER Working Paper Series. National Bureau of Economic Research, Cambridge, MA

Simon Kl, Kaestner R (2003) Do minimum wages affect non-wage job attributes? Evidence on fringe benefits and working conditions. National Bureau of Economic Research

Stock JH, Wright JH, Yogo M (2002) A survey of weak instruments and weak identification in generalized method of moments. J Bus Econ Stat 20:518-529

Whitmore H, Gabel JR, Pickreign J, McDevitt R (2011) The individual insurance market before reform: low premiums and low benefits. Med Care Res Rev 68:594-606

Wooldridge JM (2010) Econometric analysis of cross section and panel data. The MIT Press Princeton, NY

Zimmerman FJ, Katon W (2005) Socioeconomic status, depression disparities, and financial strain: what lies behind the income-depression relationship? Health Econ 14:1197-1215

10.1186/2193-9004-3-19

Cite this article as: Maclean: Does leaving school in an economic downturn impact access to employer-sponsored health insurance? IZA Journal of Labor Policy 2014, 3:19

\section{Submit your manuscript to a SpringerOpen ${ }^{\circ}$} journal and benefit from:

- Convenient online submission

Rigorous peer review

- Immediate publication on acceptance

- Open access: articles freely available online

- High visibility within the field

Retaining the copyright to your article

Submit your next manuscript at $\boldsymbol{\nabla}$ springeropen.com 